\title{
Why Do Male Tree Weta Aggressively Evict Females from Galleries After Mating?
}

\author{
Clint D. Kelly
}

Department of Biology, University of Toronto at Mississauga, Mississauga, ON, Canada, and School of Botany and Zoology, Australian National University, Canberra, Australia

\author{
Correspondence \\ Clint Kelly, Department of Psychology, \\ Dalhousie University, Halifax, NS B3H 4J1, \\ Canada. E-mail: clint.kelly@anu.edu.au \\ Received: August 7, 2007 \\ Initial acceptance: September 4, 2007 \\ Final acceptance: October 17, 2007 \\ (K. Reinhold) \\ doi: 10.1111/j.1439-0310.2007.01451.x
}

\begin{abstract}
The sexually dimorphic Wellington tree weta (Hemideina crassidens Blanchard) (Orthoptera: Anostostomatidae) is a harem-defending polygynous insect in which males use their enormous mandibles to fight conspecifics for access to harems residing in tree cavities (gallery). Tree weta ejaculates (spermatophores) do not include a nuptial meal (spermatophylax) to delay removal by females as in some ensiferan Orthoptera. Consequently, male tree weta are predicted to remain with their mates post-copula to ensure complete sperm transfer. Contrary to prediction, however, males forcibly eject females from the mating site (gallery) soon after copulation. Results suggest that forcible ejection occurs apparently because females consume the previous spermatophore if either the resident male or a rival initiates a subsequent copulation attempt. Thus, ejection appears to reduce the resident male's risk that his ejaculate will be eaten and his mate will copulate with another male.
\end{abstract}

\section{Introduction}

Post-copulatory association between males and females is widespread among insects (Alcock 1994), including Orthoptera (Brown \& Gwynne 1997). These associations can serve many functions including guarding the mate from rival males and enhancing the transfer of sperm (Thornhill 1984; Alcock 1994; Simmons 2001).

Instead of associating directly with the female, males in some ensiferan orthopterans (crickets and allies) provide nutritious glandular products to the female in the form of a spermatophylax that in some species functions to distract her from the sperm-containing (and proteinaceous) ampulla (reviewed in Gwynne 2001; Simmons 2001; Vahed 1998). Not surprisingly, larger spermatophylaces require more time to consume and allow for more sperm to enter the female (Gwynne 2001). Therefore, because males need not remain with the female to ensure that she does not remove the sperm ampulla, these nuptial meals permit males to leave the female immediately after mating. However, exceptions are known in which males provide a nuptial meal and yet remain with the female (e.g. the anostostomatid Hemiandrus, Gwynne 2004; gryllid Gryllodes supplicans, Sakaluk 1991).

In some ensiferan species, the spermatophylax has been lost (Gwynne 1995) and in these Boldyrev (1915) hypothesized that males should guard (i.e. remain with the female) thus ensuring that the mated female does not remove the spermatophore ampulla. Where mate guarding occurs, males will typically guard a female until sufficient time has passed to permit the ejaculate to enter her reproductive tract (Simmons 2001).

The Wellington tree weta, Hemideina crassidens (Orthoptera: Anostostomatidae), is a flightless, nocturnal ensiferan with a much-reduced spermatophylax that does not protrude from beneath the mated female's subgenital plate (Gwynne 1995, 1997; Stringer 2001). This lack of food gift suggests that males should guard mates; however, anecdotal evidence indicates that males actually exhibit 
post-copulatory aggression toward recently mated females and forcibly evict their mates from mating sites (tree cavities; hereafter, galleries) (Field $\&$ Jarman 2001).

Hemideina crassidens exhibits a harem-defense, polygynous mating system and exceptionally pronounced sexual dimorphism. Males use their enormous mandibles as weapons in fights with rivals over access to groups of females residing in galleries with males having larger weaponry being more successful (Kelly 2005, 2006a,c). Galleries are year-round diurnal refuges for both sexes and are important to male reproductive success because males are unlikely to encounter females away from galleries (i.e. in canopy or on ground). Galleries are neither oviposition nor foraging sites and a significant proportion is empty at any given time (Kelly 2006 b). Mating typically occurs in or near the gallery entrance at night and during the day with the latter copulations always occurring in the gallery (Field \& Jarman 2001). Inside a gallery, a female's ability to move her legs is restricted and this, in turn, appears to reduce her ability to resist a male's mating attempts (C. D. Kelly, Australian National University, Canberra, pers. obs.). Copulation typically requires $<2$ min (Stringer 2001), but spermatophores require approx. $5 \mathrm{~h}$ to completely empty (i.e. spermatophore is no longer visible under female's subgenital plate) into the female's reproductive tract (C. D. Kelly, Australian National University, Canberra, pers. obs.).

Here, I confirm that male Wellington tree weta aggressively evict females after copulation (i.e. do not exhibit any post-insemination association) and as well as test hypotheses explaining this unusual behavior. I tested whether (a) males forgo contact mate guarding because female tree weta do not consume the spermatophore after mating, (b) that resident males evict their mates from galleries to avoid remating with the same female and/or to reduce the likelihood that a rival will remove the resident's spermatophore and insert his own.

\section{Materials and Methods}

This study was conducted in the laboratory during Apr. and May in 2004 and 2006 and in the field during Apr. and May in 2003 at Te Hoiere/Maud Island $\left(41^{\circ} 02^{\prime} \mathrm{S}, \quad 173^{\circ} 54^{\prime} \mathrm{E}\right)$, a $309-\mathrm{Ha}$ scientific reserve in Pelorus Sound, New Zealand. I collected adult tree weta by scanning vegetation at night. All were uniquely marked with numbered bee tags (H. Thorne Ltd., Market Rason, UK) to facilitate identification. Captive animals were fed carrot and apple ad libitum.

\section{Do Males Evict Females After Mating?}

In each laboratory trial $(\mathrm{n}=40)$, two adult males and two adult females were placed into a mating arena (Fig. 1) approx. $4 \mathrm{~h}$ after sunset. The experimental test arena comprised a $23 \times 23 \times 45$-cm fivesided glass cage with an artificial gallery attached to plywood backing on the open side. The gallery comprised a block of wood hollowed-out in the center to form a cavity with a diameter (including the entrance hole) of $20 \mathrm{~mm}$. The cavity was 100-mm length (total gallery length can be expanded to $200 \mathrm{~mm}$, however, for this experiment only the lower section was made available to males and females by bisecting the gallery). The gallery was bisected by a removable piece of metal and was capped by an identical piece of metal; removing these metal pieces allowed me to remove the tree weta from the gallery. The bottom of the arena was covered with vermiculite to a depth of $20 \mathrm{~mm}$. Test males were put into the arena through a coverable hole above the artificial gallery and entrance to the

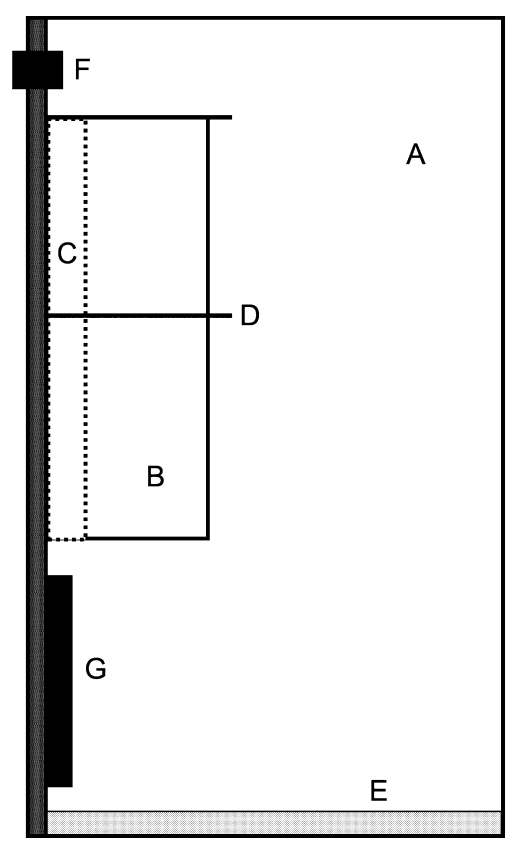

Fig. 1: Side-view of the experimental test arena showing the fivesided glass cage (A), artificial gallery (B) with a cavity (C) in its centre, the removable piece of metal bisecting the gallery (D), vermiculite floor-covering (E), coverable access hole (F) and a stick to facilitate entrance to the gallery $(\mathrm{G})$. 
gallery was facilitated by a short stick glued to the plywood below the entrance/exit hole.

All behavioral interactions were observed in complete darkness with matings recorded using a digital video camera (Sony 420; Sony, Toronto, ON, Canada) with infrared. Mating typically occurred $<4 \mathrm{~h}$ after the trial began. I noted that males could remain quiescent for several hours after introduction to the test arena; hence, I used two males in each trial to increase the likelihood of having active individuals and observing a mating. All weta were individually isolated for at least $2 \mathrm{~d}$ prior to each trial to standardize recent mating and feeding history as well as experience with conspecifics.

\section{Activity at Galleries in the Wild}

In the field on 25 nights (within $6 \mathrm{~h}$ of sunset), I placed a video camera (see above) fitted on a tripod in front of the artificial galleries attached to trees. I recorded at one to six galleries per night (18 different galleries used in study) for 40 recordings. Each recording was 60-120 min in duration for a total of approx. $67 \mathrm{~h}$ of recorded observation.

\section{Do Rivals Remove the Resident's Spermatophore?}

To test whether rivals remove spermatophores and if females remain sexually receptive after mating, I simulated a situation in the laboratory in which a resident male mates and then is usurped by a rival. In each of 50 trials, a (resident) male was randomly paired with a female in a clear plastic container ( $c a$. $19 \times 12 \times 12 \mathrm{~cm})$ with a perforated lid and was observed until copulation (confirmed by the presence of a spermatophore under the female's subgenital plate) or $1 \mathrm{~h}$ had elapsed. Immediately after copulation, the resident male was removed and replaced with a randomly chosen rival. The new pair was observed until copulation occurred or $1 \mathrm{~h}$ had elapsed.

\section{Do Resident Males Remate Their Partners?}

To test whether males recognize and avoid mating with previous mates (e.g. using chemosensory cues, Tregenza \& Wedell 1997), I simulated a situation in which a resident male mates and then remains with his partner in the gallery using a modification of the above protocol. Again, in each of 50 trials, a male was randomly paired with a female and allowed to mate; however, I then removed the male immediately after copulation and placed him into a separate plastic container for $\mathrm{l} \mathrm{h}$ (the maximum duration of male refractory period in this species, C. D. Kelly, Australian National University, Canberra, unpubl. data). His removal reduced stress and injury to females because of male post-copulatory aggression (see below). After $1 \mathrm{~h}$, the male was returned to the female and was observed until copulation occurred or $1 \mathrm{~h}$ elapsed.

In the two latter experiments, food and water were not provided during trials and, 2 days prior to each trial, test males were individually isolated while females were housed communally in a large cage provided with oviposition substrate. A different adult female and male were used in each trial. Both experiments were conducted concurrently and were performed at night under red light.

\section{Sperm Number and Spermatophore Attachment Time}

To determine whether males evict mates while the attached spermatophore still contains sperm, I estimated the number of sperm in spermatophores either immediately, 1 or $2 \mathrm{~h}$ after copulation using the set-up described for the two latter experiments. I chose these post-copula times to conservatively bracket the window of time within which female eviction occurs. After copulation, I removed the male to eliminate consumption of the spermatophore (explanation below) and kept the female in the container for the required time. I estimated sperm number by removing the spermatophore with fine forceps and placing it in an Eppendorf tube containing $1.5 \mathrm{ml}$ of water. I gently crushed the spermatophore with the forceps, vigorously shook the tube for $1 \mathrm{~min}$ to further break apart the spermatodesms (connected bundles of sperm), extracted $1 \mu \mathrm{l}$ from the middle of the solution, spread it over a microscope slide and allowed it to air-dry. I then took 20 photographs at various locations within the sample using a digital camera-mounted microscope (100x magnification) and counted all sperm heads.

Fisher's exact test was used to test for differences between two proportions. All tests were two-tailed with $\alpha=0.05$. Means are presented \pm 1 SE.

\section{Results}

\section{Do Males Evict Females After Mating?}

In 15 of 40 trials, the resident male copulated. In each case, the male entered the cavity and immediately attempted to extract the resident female by pulling her hind legs and ovipositor. Females always 
resisted by kicking the intruding male and climbing further into the cavity. Males would pull females partially out of the gallery, typically with only the female's abdomen protruding, lift her subgenital plate and insert a spermatophore.

Within seconds $(\widetilde{\mathrm{x}}=11.0 \mathrm{~s}$, range: $0-1800 \mathrm{~s})$ after copulation ended, either one of four events occurred; the female initiated departure and attempted to re-enter the cavity $(67 \%, \mathrm{n}=10)$, the female initiated departure but did not attempt to enter the cavity $(20 \%, \mathrm{n}=3)$, the male initiated departure and wandered away from the female but returned to her within $10 \mathrm{~s}(7 \%, \mathrm{n}=1)$ or the pair was interrupted by an intruding male $(7 \%, \mathrm{n}=1)$. In all cases, the male used his mandibles to grab the female's legs and toss her to the substrate below (Supplementary Material). In the one case in which a rival male intruded upon the pair, approx. $258 \mathrm{~s}$ after copulation ended, the mated male immediately tossed the female to the substrate and engaged in combat with the intruder (neither combatant entered the gallery after the fight as both fell to the substrate during battle). In 14 cases, the mated male re-entered and remained in the cavity without the mated female. Eviction was performed by males from the full range of head sizes found on Maud Island (16.35-29.95 mm).

\section{Activity at Galleries in the Wild}

Seven different males (both resident and non-resident) were observed attempting to extract females and mate; no copulation attempt was successful. On six occasions, I observed male-male interactions at the gallery. The intruding male left after inspecting the resident in four cases while the male-male interactions twice escalated to fighting: in one instance, the apparently larger resident maintained control of the gallery whereas the intruder took over the gallery in the other fight. In none of these six cases was I able to determine whether females were present in the gallery.

\section{Do Rivals Remove the Resident's Spermatophore?}

In 13 of 50 trials, the first (resident) male copulated. In no case did the subsequently introduced rival remove the first male's spermatophore. On the contrary, in nine of 11 trials $(82 \%)$ in which the rival attempted to copulate, the female consumed the first male's spermatophore shortly after receiving a copulation attempt by the rival $(5.3 \pm 2.5 \mathrm{~min})$. Females can remain sexually receptive after copula- tion given that five rivals successfully copulated (two of them placed their spermatophore alongside that of the first male). In only two of 13 trials $(15 \%)$, the first male's spermatophore remained attached to the female.

\section{Do Resident Males Remate Their Partners?}

In 16 of 50 trials, the resident male copulated. When reintroduced an hour later, resident males did not avoid their previous mate but attempted to copulate again in eight of 16 trials $(50 \%)$. In nearly every trial $(\mathrm{n}=7)$, the female ate the male's first spermatophore $8.4 \pm 2.2 \mathrm{~min}$ after his second copulation attempt (in one trial she ate the first spermatophore prior to his re-copulation attempt). Resident males successfully re-copulated in three of eight cases. The other five males had their first spermatophore eaten and not replaced.

\section{The Costs to Residents of Gallery TakeOver}

Remarkably, in $89 \%$ of cases where a resident or rival male attempted to copulate with a recently mated female (16/18 trials pooled), the female consumed the resident male's still sperm-filled spermatophore (see below). Females that were left alone $(\mathrm{n}=10)$ by males never removed the spermatophore. Resident males had their fertilization success compromised significantly more often by rivals (11/13 trials) than when they remained with their mates (5/16 trials) (Fisher's exact test, $p=0.005)$. There was no difference between the two experiments in the proportion of copulation attempts with recently mated females $(\mathrm{p}=0.11)$.

\section{Sperm Number and Spermatophore Attachment Time}

Spermatophores contain large numbers of sperm even after being attached to the female for $2 \mathrm{~h}$; I failed to find a significant difference in the number of sperm remaining in spermatophores sampled either immediately $\left(14.0 \pm 1.4 \mathrm{sperm} / \mathrm{mm}^{2}, \mathrm{n}=30\right)$, $\mathrm{l} h(17.3 \pm 3.8, \mathrm{n}=8)$ or $2 \mathrm{~h}(15.3 \pm 1.2, \mathrm{n}=7)$ after copulation $\left(\mathrm{r}^{2}=0.024, \mathrm{~F}_{2,42}=0.52, \mathrm{p}=0.60\right)$.

\section{Discussion}

Male tree weta do not provide females with a nuptial meal as part of the spermatophore (Gwynne 1995, 1997; Stringer 2001) and are therefore expected to remain with the female after copulation to ensure that she does not consume the ejaculate 
(sensu Boldyrev 1915; see also Alcock 1994). Contrary to prediction, male Wellington tree weta do not remain with their partners after mating but instead aggressively evict them from the mating site. My experiments suggest that males do this partly to avoid having their ejaculate eaten. This argument stems from the novel observation that females consume sperm-filled spermatophores only after receiving re-copulation attempts (either by the resident or a rival male). Thus, the counter-intuitive male behavior of female eviction may in effect be a form of mate guarding (i.e. ejaculate protection).

My findings suggest that failure to evict mated females poses significant costs to residents because, if usurped, residents cannot replace their consumed spermatophore. Moreover, because females remove ejaculates, a male that remains with his mate and attempts further copulations would likely need to transfer multiple ejaculates to inseminate the female with the sperm equivalent to one spermatophore.

I argue that males expel females rather than contact mate guard because there is the possibility, particularly for males with smaller weapons, that a superior competitor will takeover the gallery (my field observations suggest that gallery usurpation occurs in approx. $20 \%$ of all resident-intruder interactions). This rival can then induce the female to consume the resident's spermatophore through copulation attempts and then transfer his own ejaculate. This is a realistic scenario because occupied galleries are attractive to mate-seeking rivals (Kelly 2006b) and mated females within a gallery are likely to have the resident's sperm-filled spermatophore attached (recall it requires $c a .5 \mathrm{~h}$ for spermatophore to empty) at the time of the takeover. Similarly, in the only other known case of male post-copulatory aggression toward females, male Leistotrophus versicolor beetles aggressively drive female mates away from the mate-location site (dung resource) to reduce remating by rivals (Alcock \& Forsyth 1988).

But are there not costs to resident males that evict females? I suggest two reasons why any such costs are minimal compared to allowing females to remain in the gallery. Firstly, rivals are unlikely to encounter a recently mated female in the canopy as tree weta densities are low in the wild. Even if they do, they are unlikely to achieve copulation, which is difficult to complete outside of galleries (C. D. Kelly, Australian National University, Canberra, pers. obs.). Secondly, a significant proportion of galleries in the wild are empty and females prefer to occupy empty refuges (Kelly 2006b); thus, females are unlikely to reside with another male immedi- ately post-copula. So, eviction is likely to provide more than sufficient time for the spermatophore to be completely emptied before the female encounters another male.

The fitness benefits derived by females in consuming the spermatophores are not known. Although, male weta do not provide a food gift with their spermatophore, there could be some nutritive value in the relatively large (2-mm diameter) ejaculate. Alternatively, perhaps spermatophore-consumption is a form of cryptic female choice for genetic benefits (Eberhard 1996) whereby females consume the ejaculate of the competitively inferior male (the defeated resident) and bias paternity toward the male that usurped the gallery. Two lines of evidence suggest that females do not suffer fitness costs (i.e. sperm limitation) when they consume spermatophores. Firstly, sperm counts of the female sperm storage organ (spermathecae) of 54 wild-caught females showed that a significant proportion of females stored sperm (C. D. Kelly, Australian National University, Canberra, unpubl. data). Moreover, females are long-lived (ca. 1 yr as an adult) and mate multiply over a relatively short-time period (i.e. days) suggesting that they have many opportunities to acquire sperm (Ordish 1992).

\section{Acknowledgements}

Darryl Gwynne, Michael Jennions, Klaus Reinhold and two anonymous referees provided comments on this and earlier drafts. I thank Steve Ward and Karen Mayhew of the New Zealand, Department of Conservation for logistical support on Maud Island. This study was supported by a Sigma Xi grant-inaid of research and an ANU Faculty of Science support grant to the author and by grants from NSERC and National Geographic Society to Darryl Gwynne.

\section{Literature Cited}

Alcock, J. 1994: Postinsemination associations between males and females in insects: the mate-guarding hypothesis. Annu. Rev. Entomol. 39, 1-21.

Alcock, J. \& Forsyth, A. 1988: Post-copulatory aggression toward their mates by males of the rove beetle Leistotrophus versicolor (Coleoptera, Staphylinidae). Behav. Ecol. Sociobiol. 22, 303-308.

Boldyrev, B. T. 1915: Contributions à l'étude de la structure des spermatophores et des particularitès de la copulation chez Locustodea et Gryllodea. Horae Societatis Entomol. Rossicae 6, 1-245. 
Brown, W. D. \& Gwynne, D. T. 1997: Evolution of mating in crickets, katydids and wetas (Ensifera). In: The Bionomics of Grasshoppers, Katydids and Their Kin (Gangwere, S. K., Muralirangan, M. C. \& Muralirangen, M., eds). CAB International, Wallingford, Oxon, UK, pp. 281-314.

Eberhard, W. G. 1996: Female Control: Sexual Selection by Cryptic Female Choice. Princeton Univ. Press, Princeton, N.J.

Field, L. H. \& Jarman, T. H. 2001: Mating behaviour. In: The Biology of Wetas, King Crickets and their Allies (Field, L. H., ed.). CAB International, Wallingford, Oxon, UK, pp. 317-332.

Gwynne, D. T. 1995: Phylogeny of the Ensifera (Orthoptera): a hypothesis supporting multiple origins of acoustical signalling, complex spermatophores and maternal care in crickets, katydids, and weta. J. Orthop. Res. 4, 203-218.

Gwynne, D. T. 1997: The evolution of edible 'sperm sacs' and other forms of courtship feeding in crickets, katydids and their kin (Orthoptera: Ensifera). In: The Evolution of Mating Systems in Insects and Arachnids (Choe, J. C. \& Crespi, B. J., eds). Cambridge Univ. Press, Cambridge, pp. 110-129.

Gwynne, D. T. 2001: Katydids and Bush-Crickets: Reproductive Behavior and Evolution of the Tettigoniidae. Cornell Univ. Press, Ithaca.

Gwynne, D. T. 2004: Reproductive behavior of ground weta (Orthoptera: Anostostomatidae): drumming behavior, nuptial feeding, post-copulatory guarding and maternal care. J. Kans. Entomol. Soc. 77, $414-428$.

Kelly, C. D. 2005: Allometry and sexual selection of male weaponry in Wellington tree weta, Hemideina crassidens. Behav. Ecol. 16, 145-152.

Kelly, C. D. 2006a: Fighting for harems: assessment strategies during male-male contests in the sexually dimorphic Wellington tree weta. Anim. Behav. 72, $727-736$

Kelly, C. D. 2006b: Resource quality or harem size: what influences male tenure at refuge sites in tree weta (Orthoptera: Anostostomatidae)? Behav. Ecol. Sociobiol. 60, 175-183.

Kelly, C. D. 2006c: The relationship between resource control, association with females and male weapon size in a male-dominance insect. Ethology 112, 362-369.

Ordish, R. G. 1992: Aggregation and communication of the Wellington weta Hemideina crassidens (Blanchard)
(Orthoptera: Stenopelamatidae). N. Z. Entomol. 15, $1-8$.

Sakaluk, S. K. 1991: Post-copulatory mate guarding in decorated crickets. Anim. Behav. 41, 207-216.

Simmons, L. W. 2001: Sperm Competition and Its Evolutionary Consequences in the Insects. Princeton Univ. Press, Princeton.

Stringer, I. A. N. 2001: The reproductive biology and the eggs of New Zealand Anostostomatidae. In: The Biology of Wetas, King Crickets and their Allies (Field, L. H., ed.). CAB International, Wallingford, pp. 379-397.

Thornhill, R. 1984: Alternative hypotheses for traits believed to have evolved by sperm competition. In: Sperm Competition and the Evolution of Animal Mating Systems (Smith, R. L., ed.). Academic Press, London, pp. 151-178.

Tregenza, T. \& Wedell, N. 1997: Definitive evidence for cuticular pheromones in a cricket. Anim. Behav. 54, 979-984.

Vahed, K. 1998: The function of nuptial feeding in insects: review of empirical studies. Biol. Rev. 73, 43-78.

\section{Supplementary material}

The following supplementary material is available for this article:

Video Clip S1: Male post-insemination aggression toward a female. This sequence shows the male removing his genitalia from the female (she is partially in the gallery) with the female then entering gallery followed by the male. The male then uses his mandibles to pull the female out of the gallery by her hind tibia. The female then begins to climb the side of gallery's exterior with the male pursuing her. He grabs the female's hind tibia and tosses her from gallery.

This material is available as part of the online article from: http//www.blackwell-synergy.com/doi/abs/ 10.1111/j.1439.0310.2007.01451.x (This link will take you to the article abstract).

Please note: Blackwell Publishing are not responsible for the content or functionality of any supplementary materials supplied by the authors. Any queries (other than missing martial) should be directed to the corresponding author for the article. 